\title{
Aspectos gerais do manejo do tratamento de pacientes com esquizofrenia
}

Itiro Shirakaw a

Departamento de Psiquiatria da Unifesp/EPM

A esquizofrenia é um transtorno de evolução crônica. Costuma comprometer a vida do paciente, torná-lo frágil diante de situações estressantes e aumentar o risco de suicídio. Assim, exige um acompanhamento do paciente em longo prazo e que o psiquiatra faça um planejamento para segui-lo ao longo do tempo. $\mathrm{O}$ objetivo principal do acompanhamento psiquiátrico é a prevenção de recaídas, pois essas contribuem para a deterioração do paciente. Como objetivos secundários estão a prevenção do suicídio, a reabilitação do paciente e a diminuição do estresse familiar. $\mathrm{O}$ sucesso do tratamento depende da adesão do paciente. Mesmo após várias crises e remissões, os pacientes param de tomar os antipsicóticos e voltam a ter recaídas. A relação médico-paciente e o vínculo devem ser trabalhados constantemente para o êxito do acompanhamento psiquiátrico. As estratégias do tratamento variam conforme o paciente, sua família, a fase e a gravidade da doença.

\section{Fase aguda}

O paciente chega ao psiquiatra no momento de crise. É quando se inicia o acompanhamento psiquiátrico. Na primeira consulta é importante atender antes o paciente e depois o familiar, pois é o primeiro momento para se trabalhar o vínculo. Não importa que o paciente esteja desorganizado, desagregado, agitado ou catatônico. É a primeira oportunidade para mostrar que se está ao lado dele e não da família. O acompanhante deve ser introduzido na sala de consulta na segunda metade, para prestar esclarecimentos complementares e ser orientado sobre a conduta a ser tomada.

A primeira consulta é necessariamente longa. Deve-se colher a anamnese subjetiva, observar e esmiuçar a psicopatologia e complementar com dados fornecidos pelos familiares. Sempre que possível, também efetuar o exame clínico e verificar a necessidade de exames complementares. Em caso de dúvida, solicitar a avaliação neurológica.

A conduta a seguir dependerá do caso e da sintomatologia manifesta. A decisão de internação é tomada quando não houver suporte familiar ou a crise for muito intensa e representar risco para o paciente e seus familiares. A internação deve ser a mais curta possível (15 a 30 dias) e manejada para buscar a dose ideal do antipsicótico e para aprofundar o vínculo com o paciente. Assim que melhorar a agitação ou agressividade, é possível o acompanhamento ambulatorial, mesmo que a remissão total não tenha ocorrido. Para isso são necessários o apoio e o esclarecimento da família quanto à história natural da doença.

Quando há predominância de sintomas positivos e de agitação psicomotora deve-se escolher um antipsicótico de alta potência. A dose ideal deve ser tateada, sendo importante lembrar que a melhora é lenta. Deve-se evitar um rápido aumento da dose, pois o aparecimento do efeito antipsicótico é gradual. Estudos de PET (tomografia por emissão de pósitrons) e de nível plasmático mostram que a dose do antipsicótico deve variar entre $10 \mathrm{mg}$ e 20 mg de haloperidol ou doses equivalentes. Nessas doses, todos os receptores ficam ocupados, e doses maiores só aumentam as possibilidades de distonias e discinesias. No primeiro surto, a dose deve ser menor ainda. Tratando-se de paciente que nunca tomou medicação antipsicótica, doses de $2 \mathrm{mg}$ a $5 \mathrm{mg}$ de haloperidol ou equivalentes são suficientes. Igualmente, em pacientes idosos as doses devem ser as mais baixas possíveis. Para o controle da agitação, enquanto não houver melhora pela lenta ação do antipsicótico, é melhor associar o lorazepam ou clonazepam de $2 \mathrm{mg} / \mathrm{dia}$ a $6 \mathrm{mg} / \mathrm{dia}$, que devem ser retirados assim que haja melhora clínica. Os anticolinérgicos podem ser associados no início do tratamento para prevenir distonias agudas, que podem levar à não-adesão ao tratamento. Após a remissão do surto, com a redução da dose do antipsicótico, o anticolinérgico deve ser retirado, pois sua manutenção em longo prazo facilita a instalação da discinesia tardia. Deve-se procurar a dose mínima eficaz do antipsicótico de manutenção.

Quando há predominância de sintomas negativos, a escolha pode recair nos novos antipsicóticos: risperidona, olanzapina, quetiapina, ziprasidona, amisulprida etc. Esses e a tioridazida são indicados para os pacientes que não responderam aos antipsicóticos convencionais ou apresentaram efeitos colaterais indesejáveis. Para os casos refratários, a clozapina deve ser sempre considerada.

\section{Fase de estabilização}

Durante a fase de estabilização, a adesão ao tratamento deve ser trabalhada em cada consulta.

O psiquiatra deve utilizar todos os recursos disponíveis para mostrar que a esquizofrenia é uma doença crônica, que necessita de tratamento por prazo indeterminado. Deve-se mostrar que não vale a pena interromper a medicação, pois cada recaída comprometerá a vida do paciente um pouco mais. Depende de cada situação, e da sensibilidade do médico em escolher o momento adequado, discutir as causas, a evolução e confrontar o delírio. A discussão e a revelação do diagnóstico só devem ser feitas quando o paciente estiver preparado e a aliança terapêutica estiver bem estabelecida. Deve-se trabalhar 
a conscientização e a aceitação da doença. A experiência clínica mostra que a aceitação da doença e o insight resultam em um prognóstico melhor. O objetivo final da conscientização da doença é a colaboração do paciente com o tratamento. Quando ele aceita tomar a medicação responsavelmente e busca os caminhos para sua reabilitação, as possibilidades de controle da doença aumentam. Torna-se possível, então, ajudálo a recuperar as habilidades sociais perdidas, diminuir seu isolamento, incentivá-lo a cuidar das atividades da vida diária (higiene, banho, alimentação, horas de sono, lazer) e até promover a volta ao trabalho. Nesse momento, o encaminhamento para abordagens psicossociais pode ser muito útil.

\section{Abordagens psicossociais}

A esquizofrenia é uma doença ampla que, além da psicopatologia, compromete a vida de relação do seu portador. Exige, em geral, o tratamento em equipe multidisciplinar. $\mathrm{O}$ psiquiatra deve ponderar que a abordagem exclusivamente médica não dá conta da questão. O tratamento psicossocial é imprescindível para voltar a organizar a vida do paciente. A modalidade da abordagem psicossocial deve ser escolhida de acordo com a evolução do quadro e das possibilidades do paciente.

\section{Psicoterapia}

Deve ter por finalidade melhorar os sintomas, prevenir as recaídas e evitar a institucionalização. Entretanto, nos momentos de crise, deve ajudar a encarar uma internação necessária como medida protetora. Bruscato ${ }^{1}$ considera que seus principais objetivos são:

1. interromper a perda da capacidade mental, preservando o contato com a realidade;

2. restaurar a capacidade de cuidar de si e de administrar sua vida, e manter o máximo de autonomia para promover o melhor ajustamento pessoal, psicológico e social possível;

3. diminuir o isolamento;

4. reconhecer e reduzir a natureza ameaçadora dos eventos da vida, para os quais existe uma sensibilidade particular;

5. conscientizar o portador sobre a realidade de seus recursos e limitações, tanto ajudando a descobrir e realizar seu potencial, quanto ajudando na aceitação de suas limitações;

6. aumentar suas defesas diante de situações estressantes, liberando recursos que, eventualmente, estejam obstruídos pela psicose e desenvolver fontes alternativas para a solução de seus problemas;

7. recuperar e promover a auto-estima, a auto-imagem e a autoconfiança, proporcionando contínuo progresso;

8. estimular a independência, os cuidados consigo mesmo em questões de higiene e capacitar o paciente para as atividades da vida diária.

A psicoterapia pode ser individual ou de grupo. A psicoterapia individual deve priorizar o apoio, por se tratar o portador de esquizofrenia de pessoa com dificuldades específicas que necessitam de suporte que o capacite a obter melhora em sua qualidade de vida. Não se recomendam psicoterapias baseadas em interpretações, com várias sessões por semana e por longos anos.
Na psicoterapia de grupo, o terapeuta deve ser ativo e monitorar o ambiente do grupo. Deve buscar temas, estimular e organizar a conversação, oferecer suporte e proteção, favorecendo a coesão grupal.

Uma modalidade de psicoterapia de grupo é o grupo operativo (GO), em que o terapeuta organiza a discussão em torno dos assuntos agendados pelos próprios participantes. O GO passa a ter função psicopedagógicapara capacitar o portador da doença a ficar instruído a respeito de suas limitações, ajudando-o na adaptação social e contribuindo para conciliar sua situação de doença com as posturas de convivência que o universo social requer.

\section{Terapia ocupacional}

É uma terapia centrada em atividades. A atividade não deve ser encarada como tendo função meramente recreativa. Sua finalidade é recuperar a capacidade de voltar a fazer algo e combater a falta de vontade. É indicada para aquelas pessoas que estão em estado de desorganização, isoladas e com a vontade comprometida. A atividade faz com que a pessoa se organize e possa desenvolver sua criatividade. Não se trata meramente de fazer uma tapeçaria, uma peça de cerâmica ou um desenho. Trata-se de concluir uma tarefa objetiva, propiciando à pessoa a constatação concreta de que ela tem capacidade para executá-la.

\section{Acompanhante terapêutico}

Nessa abordagem, o acompanhante terapêutico (às vezes designado como "amigo qualificado") é um profissional de saúde mental que vai ajudar o portador a recuperar habilidades perdidas, acompanhando-o em seu dia-a-dia. $\mathrm{O}$ acompanhante vai à casa da pessoa, sai com ela, vai ao shopping, ajuda-o a voltar a dirigir etc. É uma atividade "corpo a corpo", em que as inadequações são denunciadas até mesmo vivenciando, em conjunto, situações de constrangimento e de vergonha. Tem a finalidade de ajudar o portador a locomover-se pela cidade, estar inteirado dos preços, buscar o lazer. O acompanhante terapêutico ajuda a pavimentar o caminho para a volta à realidade. Em circunstâncias especiais, a atuação do acompanhante terapêutico pode prestar-se, em fases críticas, como uma alternativa viável a eventuais internações.

\section{Orientação familiar}

Toda doença crônica dificulta a vida do portador e sua relação com a família. Se de um lado é importante a conscientização do portador da doença para que tenha os meios para combatê-la, por outro, se a família não for igualmente conscientizada, os choques serão inevitáveis. Estudos internacionais mostram que as recaídas são mais freqüentes quando o ambiente familiar é estressante. Assim, as intervenções definidas como programas de tratamento psicopedagógico das famílias têm a finalidade de diminuir as tensões presentes no ambiente familiar e de melhorar o funcionamento social do portador. Há programas familiares que são realizados com a presença conjunta dos portadores e dos demais membros da família, enquanto outras metodologias propõem a realização de programas de orientação aos familiares sem a presença conjunta dos portadores. Em ambos os casos, esses programas são orientados para os seguintes objetivos principais: 
1. reduzir o custo da doença (por exemplo, uma família bem orientada contribui para reduzir as possibilidades de recaídas e reinternações);

2. orientar a família sobre o programa medicamentoso e de atividades da vida diária;

3. ajudar o portador a colaborar com o tratamento e a assumir responsabilidades, dentro do possível;

4. verificar se está havendo resposta ao tratamento e comunicar as mudanças que surgirem;

5. estar informado sobre os sinais e os sintomas precoces de recaídas;

6. encorajar o portador a tornar-se independente, para suprir suas necessidades básicas como casa, comida e dinheiro;

7. familiares muito exigentes devem ser orientados a serem menos exigentes;

8. familiares ausentes devem ser orientados para serem mais participantes.

\section{Abordagem psicossocial em instituições}

A evolução dos medicamentos antipsicóticos transformou o tratamento da esquizofrenia de hospitalar em ambulatorial. No entanto, em determinados momentos de crise a internação ainda pode ser útil. Caso seja necessária, a internação deve ser em curto prazo. Em geral, de 15 a 30 dias são suficientes para controlar os sintomas mais evidentes. Nesse período, é importante que a família fique em contato com o doente, leveo para casa nas licenças de fim de semana e assim que receba alta. Em alguns casos, nos momentos críticos, o hospital-dia pode ser uma alternativa à internação hospitalar.

Após a alta hospitalar, igualmente, há casos em que o hospital-dia pode ser uma boa alternativa até a remissão completa do surto. A recuperação vai sendo alcançada com a internação parcial. O doente fica durante o dia em atividades de grupo ou terapia ocupacional e, à noite, volta para casa. A alta do hospital-dia pode ser realizada de maneira gradual, com a diminuição do número de dias freqüentados por semana. A família é orientada para a seqüência dos passos até a remissão do surto e a volta do equilíbrio na vida familiar.

Os centros de atenção psicossocial (CAPS) ou os núcleos de atenção psicossocial (NAPS), centros de convivência e algu- mas associações de portadores e familiares estão organizados para atividades de reabilitação social do portador.

\section{Grupos de auto-ajuda}

Ao longo da vida, grupos de auto-ajuda como os Psicóticos Anônimos (PA) e os Amigos e Parentes dos Psicóticos Anônimos (APPA) contribuem para que os portadores e seus familiares troquem experiências, encontrem-se, apóiem-se e busquem alternativas para melhor conviver com a doença.

Para as pessoas nas quais a doença teve uma evolução mais crônica são indicadas pensões protegidas e/ou oficinas de trabalho protegidas.

Essas últimas modalidades de equipamentos sociais mencionadas são essenciais e imprescindíveis para a melhor qualidade de vida de parcela significativa dos portadores de esquizofrenia. Constituem-se como recursos indispensáveis para se atingir o ideal de que as internações hospitalares ou em hospital-dia sejam reservadas apenas para situações efetivamente críticas.

\section{Conclusões}

Para finalizar, a APA (Associação Psiquiátrica Americana) ${ }^{2}$ resume os passos para o manejo clínico do tratamento de pacientes com esquizofrenia:

1. estabelecer e manter a aliança terapêutica;

2. monitorar e acompanhar o paciente, prestando atenção aos sintomas prodrômicos de recaída;

3. promover educação sobre a esquizofrenia e seu tratamento;

4. determinar a necessidade de medicação e de intervenções psicossociais, e elaborar um plano de tratamento;

5. reforçar a adesão ao plano de tratamento;

6. incentivar a compreensão e a adaptação psicossocial, e buscar uma adaptação social compatível para cada caso;

7. ajudar a reconhecer precocemente as recaídas, promover as mudanças no tratamento e identificar fatores que precipitam ou perpetuam os surtos;

8. envidar esforços para aliviar o estresse familiar e melhorar o funcionamento familiar;

9. facilitar o acesso do paciente aos diversos serviços e coordenar os recursos destinados à saúde mental, tratamento clínico-geral, necessidades advocatícias, aposentadoria, lazer etc.

\section{Referências}

1. Bruscato WL. Psicoterapia individual na esquizofrenia. In: Shirakawa I, Chaves AC, Mari JJ, editores. O desafio da esquizofrenia. São Paulo: Lemos Editorial; 1998. p. 149-64.

2. [APA] American Psychiatric Association. Practice guideline for the treatment of pacients with schizophrenia; 1997.

3. Shirakawa I. As abordagens psicossociais. In: Louzã-Neto MR,
Shirakawa I, Barros L, editores. Esquizofrenia: dois enfoques complementares. São Paulo: Projeto Fênix; 1999. p. 33-44.

4. Shirakawa I. O ajustamento social na esquizofrenia. São Paulo: Lemos Editorial; 1991.

5. Shirakawa I. O Manejo do paciente com diagnóstico de esquizofrenia. In: Shirakawa I, Chaves AC, Mari JJ, editores. O desafio da esquizofrenia. São Paulo: Lemos Editorial; 1998. p. 273-9

Correspondência: Itiro Shirakawa

Rua Mário Cardim, 168 - CEP 04019-000 São Paulo, SP

Tel.: (0xx11) 574-0905 